2. Operation of iridectomy removed a sector of iris with greater part of cyst, but the root of the cyst at anterior region of ciliary body and root of iris remained. The open edges of the cyst came into contact, fused and the cyst re-formed and gradually enlarged. The pillars of the coloboma became opposed to the deep corneal surface and there adhered.

As the cyst re-formed, it extended from the ciliary region behind the adherent pillars of the coloboma or perhaps was instrumental in pushing these pillars forwards against the cornea. It carried with it, as it enlarged, ciliary processes on its deep or posterior surface (see drawing, and stereo-photograph, Figs. 3 and 1).

The trephine operation merely sufficed to remove a small portion of the anterior cyst wall. The edges of this opening would almost inevitably approximate one to the other on the collapse of the cyst, and quickly heal together.

As the cyst was again re-formed by secretion of fluid by its lining epithelium, the wall of the cavity was pushed a short way into the trephine opening at the corneo-scleral junction (as seen in a small number of the serial sections). The remainder of the trephine opening became sealed with fibrous tissue, as there was no leakage of fluid to keep it patent.

\title{
INTRA-CISTERNAL INJECTIONS IN THE TREATMENT OF LUETIC OPTIC ATROPHY*
}

\author{
BY \\ SANFORd R. GiFford \\ FROM THE DLFARTMENT OF OPHTHALMOLOGY, UNIVERSITY OF NEBRASKA \\ MEDICAL COLLEGE, OMAHA, NEBRASKA, U.S.A.
}

IT requires no little temerity to approach the subject of luetic atrophy, especially from the point of view of its treatment. For we were taught to believe that so-called simple luetic optic atrophy is a progressive disease, practically unaffected by treatment, and running its course to blindness in nearly every case. I believe that this view is still accepted by a large number of clinicians, as it was by us, until an experience with one patient led us to reconsider the subject, and to try out certain lines of treatment on a series of similar cases.

The experience was as follows :-.-Case I. Mr. H. 48 years old, a banker, had been taking anti-syphilitic treatment for the past fifteen years. He stated that his blood Wassermann had

* Read at the Oxford Ophthalmological Congress, July 6, 1923. 
been negative at examinations fourteen and eight months before, but that his spinal fluid had never been examined. He had noticed failure of vision in R.E. for eighteen months, and in L.E. for only the past ten days. He had not had any other neurological symptoms. Our first examination, in December, 1920 , showed vision R.E. 20/100, L.E. 20/20 with correction. In spite of this good central vision, the field was contracted to about 15 degrees all round in the left, or better eye, and in the right eye a large central scotoma prevented a satisfactory chart. Both nerves showed the picture of simply atrophy. Spinal fluid showed 20 cells per $\mathrm{cmm}$., an increase in globulin, Wassermann $3+$, and a Lange curve suggestive of tabes. He returned in a week, having used mercurial inunctions in the meanwhile. During

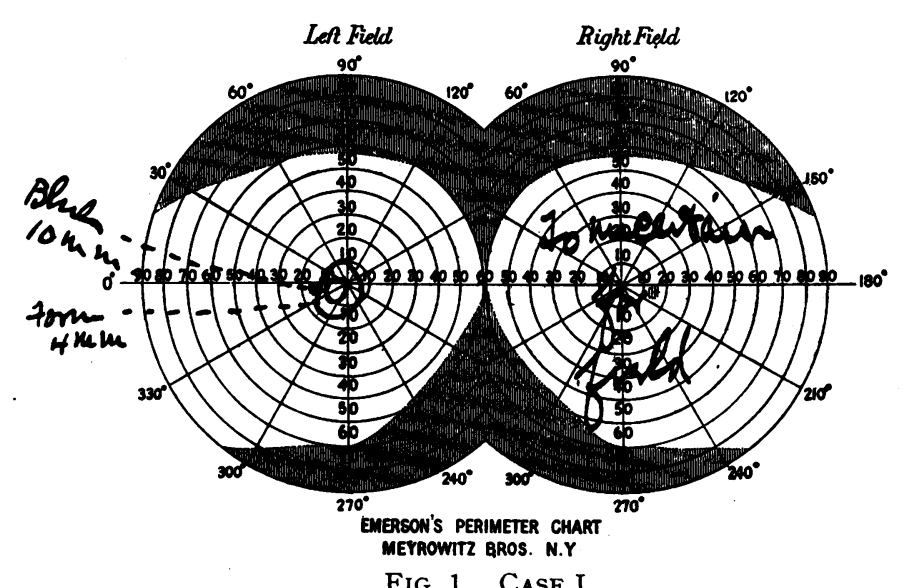

this week, vision had fallen to $20 / 200$ R.E. and $20 / 50 \mathrm{~L} . \mathrm{E}$. The field of this eye was within 10 degrees all around. (See Fig. 1.) There was no colour perception; R.E. and L.E. could not distinguish green, and saw red only at the centre. After consultation with Dr. James M. Patton, we decided that, in view of such a rapid progress, nothing but a bad prognosis was justified. We referred the patient, however, to Dr. George F. Suker, of Chicago, from whom he received four injections of $1 / 50$ grain mercury bichloride in the lateral ventricle in the course of three months. A remarkable improvement was noted following the first injection, and after two weeks, the fluid removed gave a negative Wassermann. We saw the patient after ten months, and found vision of 20/15 in both eyes with correction. All the colours were perceived in both eyes, and the fields were distinctly improved, that of the left eye extending out to 35 degrees temporally, and 
a field out to 10 degrees being obtainable in the right eye. (See Fig. 2.) Fine print was read easily, and he had no trouble in getting about, except at night. The nerves appeared the same as at our first examination. Eighteen months after his first visit, he reported by letter that vision was the same as at the last examination, and that his general health was good. 'Two and a half years after his first visit, he reported, and showed a slightly smaller field in the left eye than the one last obtained. Blood Wassermann was plus-minus and spinal fluid Wassermann negative. $\mathrm{He}$ is to be watched, with the possibility that further injections may be necessary.

Evidently, in this case, something had happened, either spontaneously or as the result of treatment, which had not only

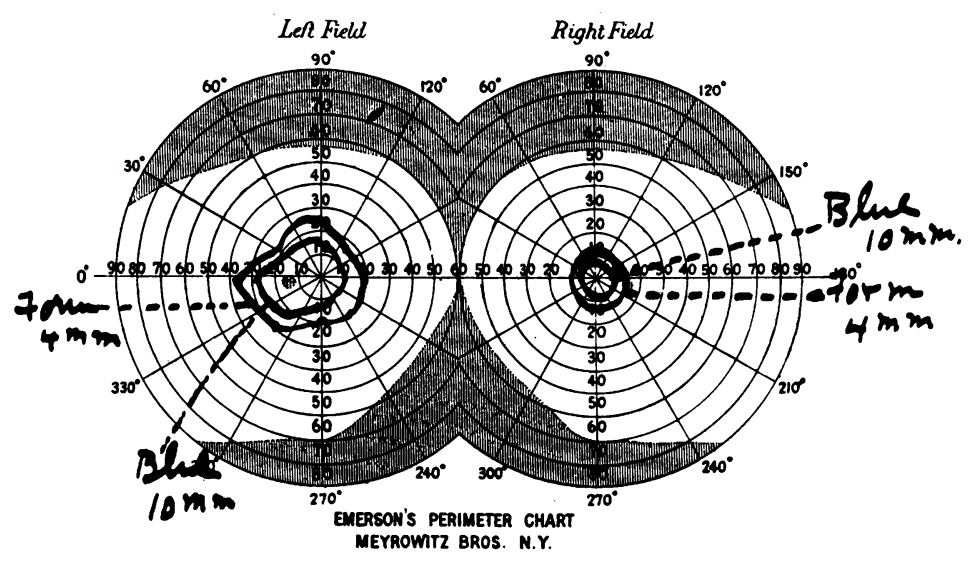

FIG. 2. CASE I.

stopped the process, at least temporarily, but had actually caused an improvement in the function of the nerve. In either case, such improvement is unintelligible if we regard the process as a simple atrophy. The whole question of treatment depends on the pathology involved.

The view that the process is a simple atrophy, due to toxins produced by syphilis elsewhere in the body, was based on the examinations of nerves by Cruveilhier, Virchow, Uhthoff, and others. These authors found simple gray degeneration of nerve fibres, without any signs of inflammation. Others, such as Moxter and von Michel, and Gliksmann, found the degenerative changes most marked in the retinal ganglion cells, and the theory was advanced of an ascending atrophy, beginning in an injury to these retinal cells by the toxins. Most of these pathological 
examinations concerned only small numbers of eyes, observed late in the disease.

Keraval and Raviart ${ }^{(1)}$, though they found evidences of degeneration in the retinal ganglion cells, found also proliferative changes in the nerve and its vessels, indicating a previous active luetic inflammation. Marie and Leri ${ }^{(2)}$ examined the nerves of 60 tabetics and paretics. In all those with atrophy they found evidences of previous active inflammation in the nerves or visual tracts. Degeneration of the retinal cells was noted, but the changes in the nerves were always more extensive, and they were convinced that the lesions could not have originated in the retina. They concluded that the first lesion in the nerve is the ordinary peri- and endo-vasculitis of tertiary syphilis, causing secondary atrophy. An even more complete investigation of the subject was made by Stargardt ${ }^{(3)}$, who was led to a similar conclusion. He examined the complete visual apparatus, brain, and in some subjects also the cord, in 21 cases of tabes and paresis, and correlated the changes with the field defects found during life. In all of the 13 cases which had shown optic atrophy during life, evidences of active luetic inflammation were found at some point in the nerves or visual tracts. These consisted in an infiltration, chiefly by plasma cells, extending into the nerves along the pial septa and the pia surrounding the nerves and chiasma, and being especially marked about the central vessels at their entrance into the nerve. In the cases of paresis and taboparesis, the brain in the neighbourhood of these foci of infiltration was usually similarly involved. The cases of pure tabes showed isolated areas of infiltration in the nerve, completely separated from the similar foci that were found in the cord. In eight early cases, showing these changes in the nerve, no changes were present in the retinal ganglion cells, which would seem to dispose effectively of the theory of a retinal origin. Stargardt concludes that luetic optic atrophy is a secondary atrophy due to the changes of late syphilis such as are found elsewhere in the body, the result, therefore, of the presence of spirochaetes. Thus primary atrophy, in the old sense, would be, in such cases, a misnomer. Since the changes usually affect the region of the chiasma first, and extend only later, if at all, into the orbital portion, the ophthalmoscopic picture of simple bptic atrophy is perfectly intelligible. The same changes were found in four cases examined by Richter(t). To Englishmen, this idea of pathogenesis should be especially acceptable on account of the work of Head and Fearnsides ${ }^{(5)}$, and of Mackintosh and Fildes ${ }^{(\sigma)}$, who showed that the difference between cerebro-spinal syphilis and so-called para-syphilis, is chiefly a difference in the location of the infiltrative process.

It is true that, as yet, practically all attempts to find spirochaetes 
in the nerve have failed. The only positive findings have been those of Igersheimer ${ }^{(7)}$ who, in eight cases of paresis and taboparesis showing optic atrophy, found small foci of spirochaetes four times in close relation to the visual apparatus. Three times they were found in the brain or meninges quite close to the chiasma or external geniculate body, and once in or very near the nerve itself. In no case, however, were masses of spirochaetes seen in the nerve, such as are found in the cortex in paresis.

A theory recently proposed by Hauptmann ${ }^{(8)}$ considers the essential lesion to be due to the destruction of brain and nerve substance by a non-specific proteolytic ferment formed by the body, the phenomenon being, therefore, analogous to that of anaphylaxis. While his theory explains quite plausibly certain perplexing peculiarities of tabo-paresis and optic atrophy, it requires the assumption of a complicated train of processes for which there is very little experimental evidence. von Hippel ${ }^{(9)}$, in the most recent review of the subject, considers this question of the pathogenesis of optic atrophy as still unsettled, though Stargardt's work contains the largest amount of positive evidence yet put forth. Paton ${ }^{(10)}$, in a very comprehensive discussion of the conflicting evidence, is certain that the toxic theory must be abandoned. In optic atrophy, according to his view, there would seem to be a parallel reaction of both parenchyma and interstitia, with spirochaetes present in both.

The practical significance of this view of pathogenesis is clear. If an active luetic process is at work, the possibility at least exists, as in any other luetic process, that it may be stopped if the spirochaetes can be killed. We cannot expect that nerve fibres already destroyed will be repaired, and some fibres already injured may go on to complete degeneration, but if the active process is stopped, those fibres which remain should survive, and vision should suffer very little further loss: It is even thinkable that an absorption of infiltrate from between the nerve fibres may allow some slightly damaged fibres to resume their function. The test of our therapeutic measures must naturally be made, not in old cases, far gone in atrophy, but in early ones, and careful perimetry in cases of suspected neuro-syphilis, or of luetic muscle palsies, seems of great importance.

The difficulty, however, as in other forms of neuro-syphilis, lies in the fact that the seat of the active process is hardly accessible by the usual modes of attack. As has been shown to be true in tabes and paresis, so in optic atrophy the organisms must be assumed to be ensconced in the nervous parenchyma where drugs given by vein can hardly reach them in effective concentration. A few authors, such as Iwaschenkoff and Nonne(11) have reportied moderate success by the intensive use of salvarsan. But these 
cases are very exceptional, and those reported were not followed for long periods. It is common to see optic atrophy develop during or after such treatment, and go on to blindness. Our cases treated intensively by salvarsan have all ended in practical blindness.

When spinal injections by the methods of Swift-Ellis and others were first reported, it seemed that this might offer a better mode of attack in optic atrophy. It was soon found, however, that though some cases of tabes were improved, and some early ones apparently cured, higher lesions, such as those of paresis and optic atrophy, did not respond so well. A few good results of spinal treatment in optic atrophy have been reported. Gennerich $^{(12)}$ mentions two cases, in one of which vision of $6 / 24$ and $6 / 12$ respectively was held the same for five years. Fordyce ${ }^{(13)}$ reports one improvement of vision from $20 / 70$ to $20 / 40$ in one eye, preserved during an observation of ten months, and another in which vision remained 20/30 for one year. Both cases had lost the sight of the other eye during general treatment. One of our cases has apparently been brought to a standstill with good vision in one eye, after such treatment, but he suffered a paralysis of both legs and the bladder after the last injection, given by a competent neurologist, from which he recovered only after several months.

Knowing what we do about the circulation of the cerebro-spinal fluid from the choroid plexus downward, the cases of failure in these higher lesions seem easier to understand than those of success. Weed ${ }^{(14)}$ has shown that coloured solutions could be forced into the sheaths of the cranial nerves only by using continued pressure for over three hours. Therapeutic injections made in the ordinary way would thus never reach the optic nerves. Schoenberg ${ }^{(15)}$, in fact, using no such continued pressure, found that the solutions seldom reached above the posterior fossa, and never stained the optic nerves. Ayer ${ }^{(16)}$, realizing this fact, injected salvarsanized serum intra-spinally, followed by saline under pressure of $400-600 \mathrm{~mm}$. of water for one hour. He reports four cases of optic atrophy held stationary for three months by this method. The use of such high continued pressure, however, would seem likely to cause severe reactions, besides its inconvenience.

In view of these facts, the plan adopted by $\mathrm{Behr}^{(17)}$ would seem in some ways more logical than intra-spinal treatment. He drained the spinal fluid at intervals during intra-venous salvarsan treatment, believing that this would increase the amount of drug reaching the nervous system from the blood-stream. He reports one early case, with a marked diminution in dark adaptation, in which this returned to normal, and remained so, with good central 
vision, during an observation of three years. One of our cases in which this was done remained stationary for three months, until he was lost sight of, but three others followed the usual course. Dercum has used spinal drainage extensively in America, and claims good results in various types of neuro-syphilis, but Stokes and Osbourne ${ }^{(18)}$, after a careful comparison of results by different methods in their patients, found spinal drainage to have little or no advantage over general treatment, while intra-spinal treatment showed distinct advantages. The question is still an open one among neurologists. Marinesco ${ }^{(19)}$ still claims good results, while Sicard ${ }^{(20)}$, who in 1899 was the first to use mercury by the spinal route, has abandoned the method, believing it to be in some cases dangerous, and to offer no advantages over general treatment. There can be no doubt, as Sicard first suggested, and Mehrtens and MacArthur ${ }^{(21)}$ have recently proved, that the effect of intra-spinal treatment is not due solely to the amount of the drug administered which reaches the nervous tissues, but partly to the irritant effect of both serum and drug, which increases the permeability of the meninges to drugs already present in the blood. Mehrtens and MacArthur detected arsenic in the spinal fluid of 92 per cent. of patients who received intra-venous and intra-spinal salvarsan, as against 43 per cent. of those who received it by vein alone. An aseptic inflammation of the meninges was produced, as shown by the greatly increased cellcount, and this hyperaemic reaction evidently favoured penetration of the drugs. It would seem, however, that this reaction would not extend much higher than the level to which the injected fluid reached, and hence that it could be produced more effectively, for our particular purpose, by intra-cranial injections.

Goebel (22) attempted to produce a concentration of the drug in the region of the nerve by applying intermittent suction to the globe. Beriel(23) injected mercury directly around the nerve with a long needle. Lowenstein ${ }^{(24)}$ produces a general reaction by actual inoculation with malarial parasites, following this by salvarsan. None of these observers has reported series of cases followed for a sufficient length of time to determine the value of his method.

In 1916 Schoenberg ${ }^{(15)}$ succeeded in staining the nerves of animals intensely by injections into the lateral ventricles. Wegeforth ${ }^{(25)}$ had shown that injections into the basal cisterna have this effect, and that if the aqueous is removed at the same time, the dye even penetrates between the nerve bundles of the papilla and reaches the retina. Schoenberg has reported five cases of optic atrophy in which salvarsanized serum was given intra-ventricularly. In most of these, the injections were resorted to only after general and spinal treatment had failed. In four 
cases, vision had failed to $10 / 200$ or less before the injections, and eventually failed further. The only early case, however, showed an increase of vision from $15 / 200$ to $20 / 70$ in the better eye, till the patient was lost sight of. Suker ${ }^{(26)}$ has used the same route, injecting, however, mercury bichloride, for a number of years. One case received six injections of $1 / 100$ to $1 / 25$ grain, and has held vision of $20 / 30$ and the same fields in both eyes for four vears. In another place ${ }^{(27)}$ he mentions four of his cases as having all shown improvement. I know of no other ophthalmologists who have reported their results with intra-cranial treatment. Among neurologists, the intra-cranial route has of late been frequently used. Hammond and Sharpe ${ }^{(28)}$ and Hamill(29) in America have reported some successes. Hamill used 100 $\mathrm{mg}$. of neosalvarsan divided between the two lateral ventricles, and points out that these large doses are well-tolerated in the cranial cavity, whereas only 2-3 $\mathrm{mg}$. can safely be given intra-spinally. Marinesco ${ }^{(19)}$ emphasizes the same fact, and uses up to $160 \mathrm{mg}$. intra-cranially. In England, Campbell and Ballance ${ }^{(30)}$ followed three cases of paresis for some years after intra-ventricular salvarsan treatments. No bad effects were seen, and one case was alive and apparently normal after five years. A case of optic atrophy who was almost blind, showed no effect of treatment. In France, Sicard and Lapointe, Marie, Levaditi and Mattel have used intra-cranial injections with varying success, Sicard having abandoned it in favour of general treatment. The very uncertain results in paresis need not imply similar ones in optic atrophy, early diagnosed, since here both pathology and clinical evidence have shown that there is often no general involvement of the nervous system, but one or more localized foci.

Following our experience in Case I, we have explained the chances afforded by intra-cranial treatment, putting the case in none too encouraging a light, to every case of definite luetic optic atrophy we have seen, where vision was still useful in one eye. With those who consented, treatment was begun at once intracranially, from three to four injections of 1/50 grain mercury bichloride being given, at intervals of ten days to three weeks, this being combined with general treatment. Some of these cases were reported before a local society in $1922^{(31)}$. Since then, we have seen several new cases, and have followed the previous cases for a year longer.

Case II.-Jack W. was a man of 35 years who had noticed vision failing steadily in both eyes for the past sixteen months, in spite of four injections of salvarsan and weekly injections of sodium cacodylate during most of this time. At the time of his primary infection five years before, he had received some antisyphilitic treatment, and was considered cured. For the past few 
months he had suffered with some girdle-like abdominal pains, and had also noticed some difficulty in urination. When first seen by us, in May, 1921, vision was 18/200 in R.E., and 2/200 in L.E. A good field could not be taken in the left eye, and the right eye showed an absolute central scotoma with a relative scotoma occupying the whole lower half of the field. (See Fig. 3.) Both nerves were quite pale, and the left almost white. Spinal fluid Wassermann was t in 0.4 and 0.8 c.c. He received three injections of $1 / 50$ grain mercury bichloride in the lateral ventricle during five weeks, besides mercury inunctions and potassium iodide. One month after the first injection the right field showed a clearing up of the relative scotoma in the lower half, and though his central vision was the same as at first, the

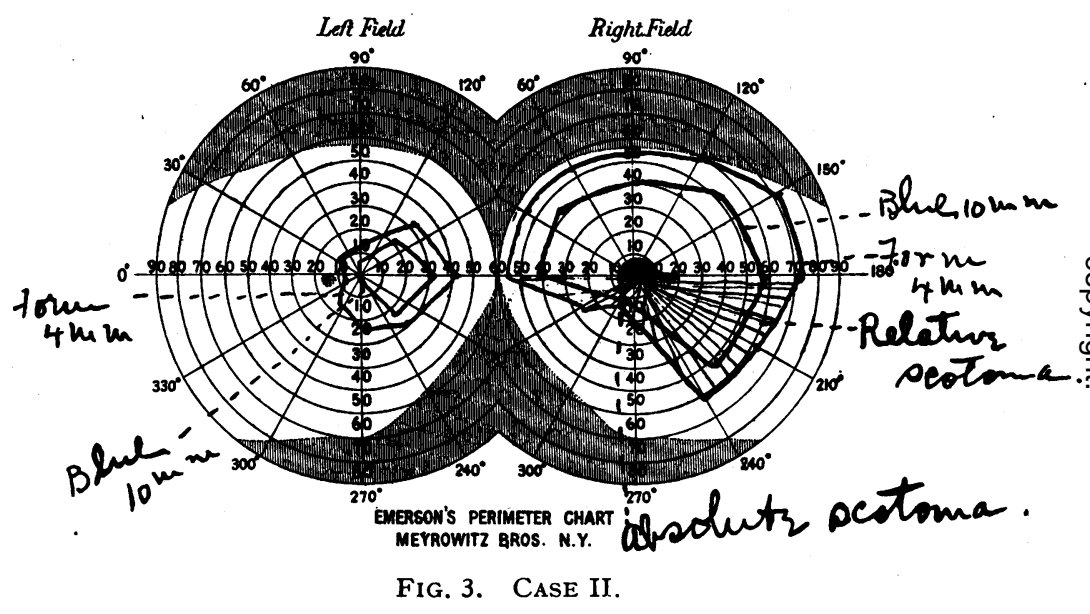

central scotoma was now only relative, so that the patient could read handwriting and large newspaper type, and could carry on his work. (See Fig. 4.) When last seen in January, 1923, vision was R.E. 19/200 and L.E. 1/200. He has had no more girdle pains or trouble with the bladder, and is in good general health. The nerves are as pale as when first seen. This was a late case in terms of the damage done, and was considered very unfavourable for treatment.

Case III.-Frank G, a man of 33 years, who was referred by Dr. Weaver of Shenandoah, Iowa, gave the history of a primary infection some years ago, when he received general treatment. He had first noticed poor vision in the right eye two months before, but believed the left eye was normal. At his first visit in February, 1921, vision in the R.E. was counting fingers at eight inches, and in the L.E. 20/30, with a defect of the lower nasal quadrant of 
the field. Both nerves were decidedly pale, the left being almost as pale as the right. Spinal fluid Wassermann was weakly positive. He received, besides mercury inunctions, salvarsan and potassium iodide, four injections during two months, the first two being given in the lateral ventricle, and the last two in the cisterna magna. Immediately after the last injection, the aqueous was withdrawn from the left eye, on the basis of Wegeforth's experience. The peripheral field of the good eve remained the same during four months' observation, but central vision failed to $20 / 50$, then to $20 / 70$. Two years after he was first seen, his doctor writes that vision is now light perception in R.E. and 20/100 in L.E., and that his blood Wassermann is weakly positive. He is still using mercurial inunctions and potassium

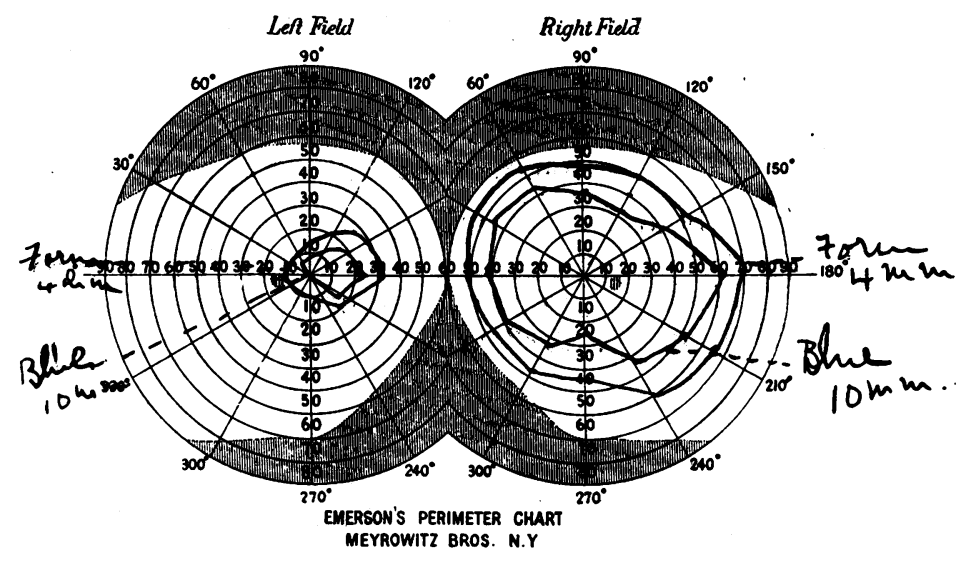

FIg. 4. CASE II.

iodide at intervals. He had developed no neurological symptoms, is able to do his work, and thinks the vision has remained the same for the past six months.

Case IV.-Max C., a man of 33 years, was first seen in September, 1922, when he complained that vision had been failing in the left eye for the past three months. We found vision 20/20 in the R.E. and 8/200 in L.E. The right field was normal, but the left showed a defect of the entire upper half and part of the lower nasal quadrant, with a relative central scotoma. (See Fig. 5.) The left nerve was decidedly atrophic, the right slightly pale in the outer half. No venereal history could be obtained, but the blood Wassermann was $4+$, and the spinal fluid Wassermann positive. Injections of mercury bichloride into the cisterna magna were given September 19, and October 10, 1922, together with intensive salvarsan, mercury and potassium iodide. One 
week after the first injection, there was a remarkable improvement of vision in the left eye, vision being $20 / 70$, with a distinct improvement in the field. (See Fig. 6.) This improvement was

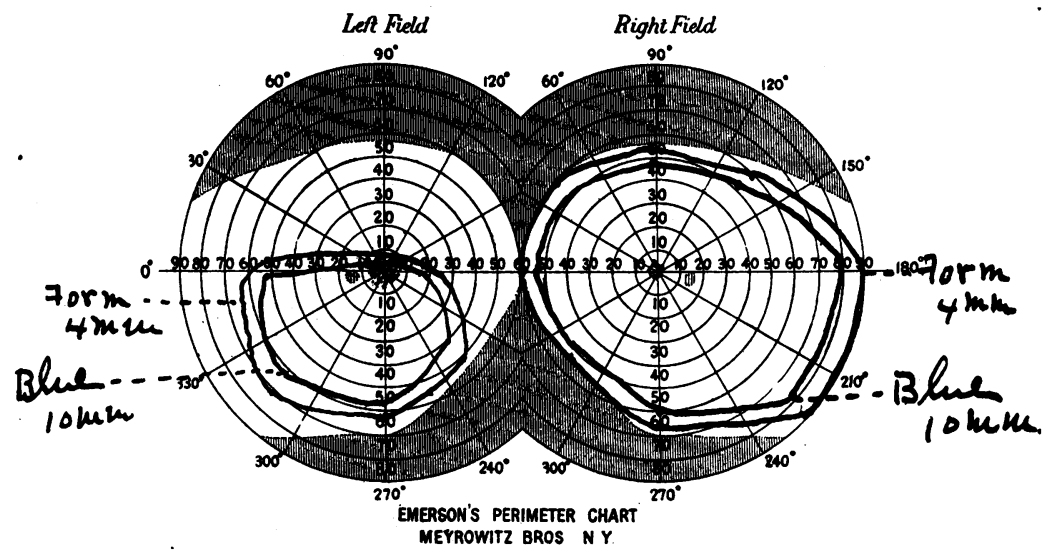

Fig. 5. CASE IV.

maintained for about two months, and a small island of form perception appeared in the upper half of the field. From this time, in spite of continued general treatment, the left eye gradually failed, until in January, 1923, vision was about the same as at

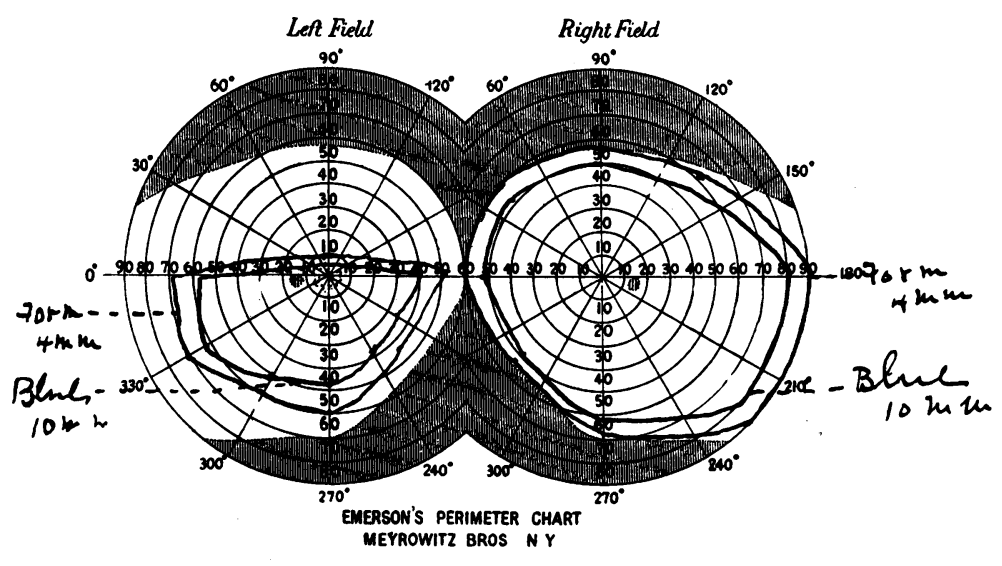

FIg. 6. CASE IV.

first, with the field smaller. (See Fig. 7.) The third injection was given in March, 1923, and general treatment continued in milder form. When last seen, the condition was about as in January. 'The right eye has never shown any involvement of the field or central vision, and the slight pallor, which is within physiological limits, has never changed. 
Case V.-Mr. L., a man of 44 years, was referred by Dr. Gittins of Sioux City, Iowa, in April, 1923. Six weeks previously he had noticed the first failure of vision in the right eye, which failed so rapidly that in ten days he considered that it was blind. His doctor reported that his blood and spinal Wassermann tests had been positive, and that he had received intensive treatment with

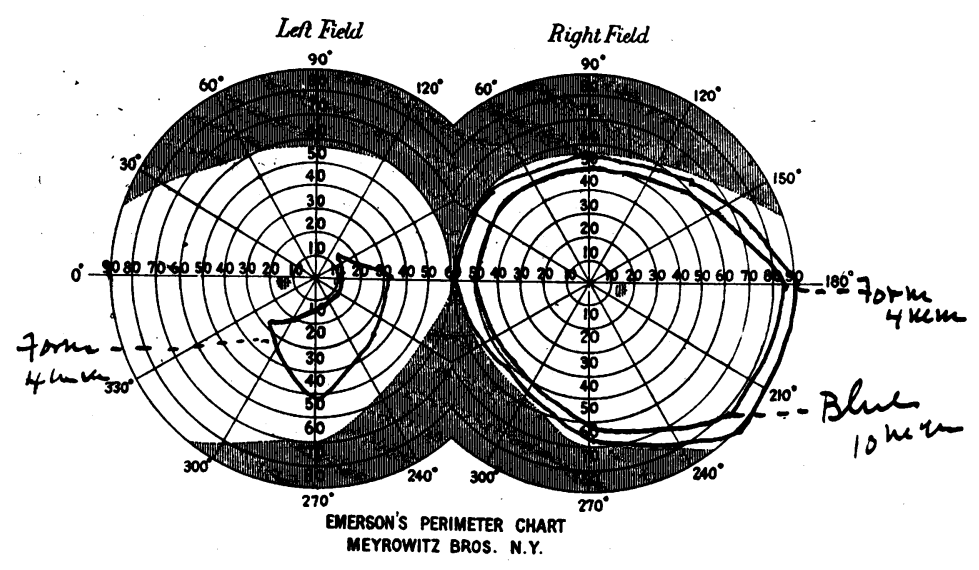

Fig. 7. CASE IV.

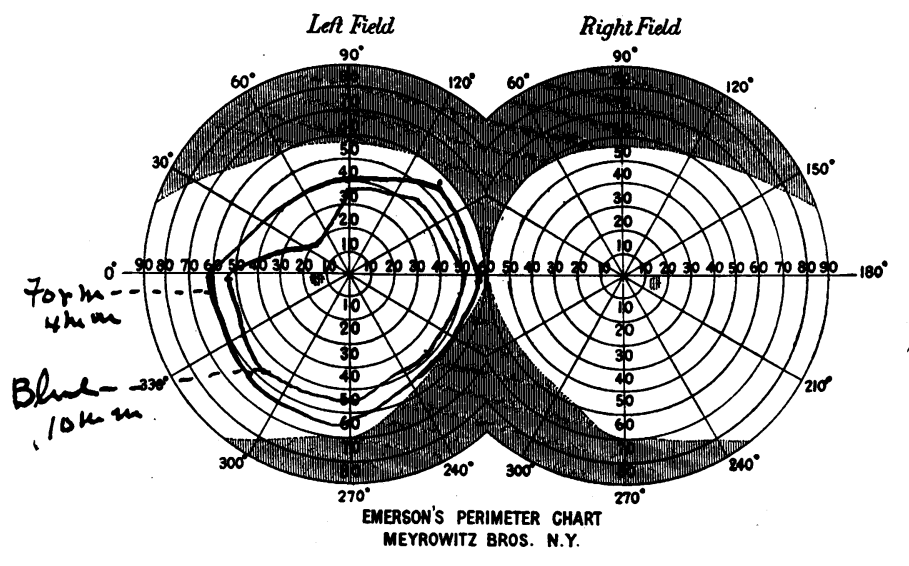

FIG. 8. CASE V.

salvarsan and mercury for the past month. The week before we saw him, while still under treatment, a slight limitation of the upper temporal part of the left field had been noticed by the patient, which was confirmed by perimetry. Some girdle pains and trouble with the bladder were complained of. At his first visit, vision in R.E. was light perception, and in L.E. 20/20, with a defect in the upper temporal quadrant, especially for colours. (See Fig. 8.) The right nerve was white, the left normal. 
Injections were given into the cisterna magna on the 3rd and 12th of April, being followed the next day by an intra-venous injection of salvarsan, on the theory that the drug would penetrate the meninges more readily during the reaction from the injection. A few days after the second injection vision was 20/20 in L.E., and there was a distinct improvement in the field. (See Fig. 9.) Between injections his general treatment was carried on at home. $\mathrm{He}$ has since received two more injections, and vision and field remain the same as last recorded.

Case VI.-John B, a man of 63 years, was first seen in February, 1923. Vision in the left eye had been poor for two years, but had been good in the right eye until four weeks ago, since when it has failed rapidly. He gave a history of luetic infection some

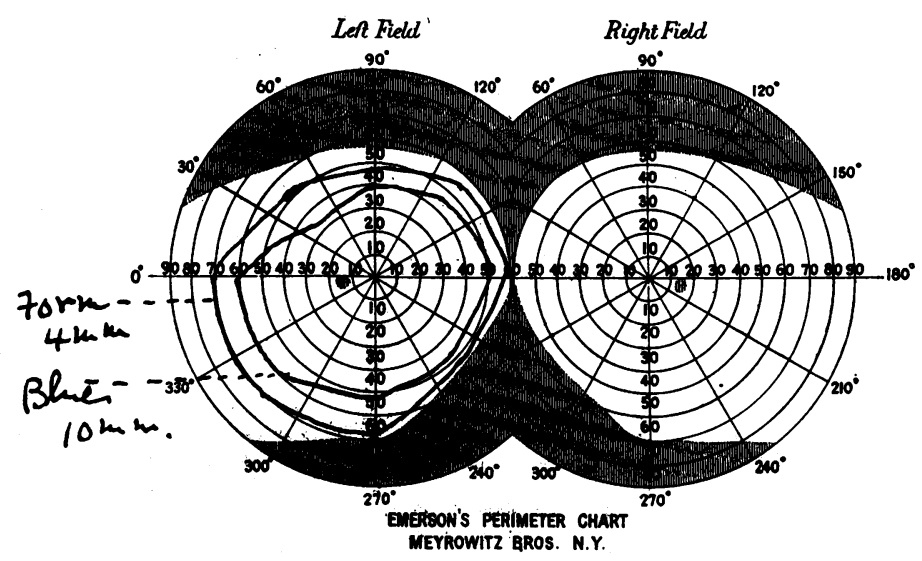

FIg. 9. CASE V.

years before, had taken several courses salvarsan and mercury, and had been told that his blood test was negative. At his first visit, vision was recorded as hand movements in L.E. with fair projection, and light perception in R.E. In the right eye, the only one in which a field could be obtained, this was contracted to a small central area almost entirely inside of 10 degrees. (From subsequent examinatiohs, it is evident that in taking his vision the assistant had over-looked this small area, so that central vision may have been, and probably was, as good at this examination as it subsequently proved to be.) (See Fig. 10.) Both pupils 'reacted very sluggishly to light, and both nerves were very white, with areas of retinal atrophy around both papillae. Though spinal fluid examination was normal in all respects, in view of the luetic history, and the rapid fall in vision, he was given three injections of mercury, the first two a week apart, the third after two months. 
Each injection was followed the next day by salvarsan, and mercury inunctions were used in the meantime. Twenty-four hours after the first reaction, the spinal fluid was withdrawn, and showed the presence of a marked reaction, with 300 cells per $\mathrm{cmm}$., and a large increase in globulin. After the second injection,

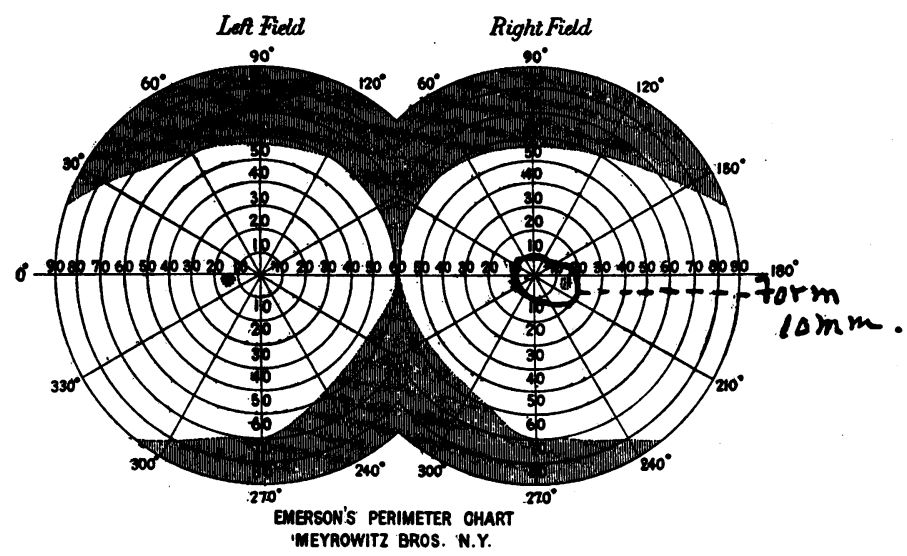

Fig. 10. CASE VI.

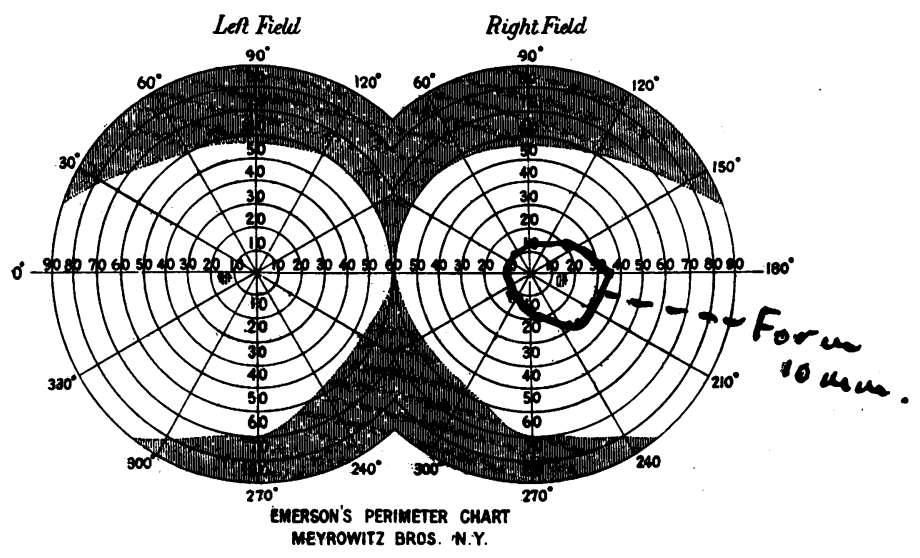

FIg. 11. CASE VI.

vision subjectively was pronounced better, central vision was $20 / 30$, and the field extended out beyond 30 degrees temporally, with considerable increase both up and down. (See Fig. 11.) There was no change in the vision of the poorer eye, nor in the appearance of the nerves. The last three cases have none of them been observed long enough to justify any conclusion as to the permanent effect of treatment. In two other cases, one injection 
was given, after which the patients disappeared from treatment. One, an advanced case when first seen, appeared after eight months with only light perception in each eye, and no further treatment was given. A third case, with vision of 5/200 in each eye, and a cell-count and other signs suggestive of paresis was given two injections, without any effect on his vision, and died a year later, apparently from general paresis, having become practically blind shortly before his death.

None of these cases has been watched long enough to assert that the process has been permanently stopped, and we hope to be able to follow them and to report on their condition after three to five years.

There is no question that, clinically, a marked improvement occurred in the vision of five of our cases, even if this did prove, in one case at least, to be only temporary. In thinking of the mode of action of this form of treatment, and of its possible superiority over other methods, it is evident that several factors may play a part. First, mercury injected into the basal cisterna would reach the meninges and pial septa of the nerve by the shortest possible route. If we drain the cerebro-spinal fluid and use $10 \mathrm{cc}$. of it in re-injection, our theoretical concentration of $1 / 7,500$ may quite possibly have a direct effect on the spirochaetes. Secondly, such an injection increases the permeability of the meninges to drugs in the blood-stream in two ways, by the simple drainage of the fluid, and by the aseptic inflammation set up by the drug injected, and this increased permeability is in the part of the meninges where it is most desired. The practice of giving salvarsan by vein the day following each injection would seem, theoretically, to be a valuable addition to our regimen.

Thirdly, the increased permeability may be assumed to allow the passage of much greater quantities of anti-bodies than normal from the blood stream into the cerebro-spinal cavities, which may be most important.

Conclusions :- -1 . Intra-cranial injections of mercury bichloride have given, in our hands, better results than other methods previously tried. Several cases have apparently been brought to a standstill with useful vision for periods of one to two and a half years. A negative Wassermann has often been obtained by such treatment.

2. Intra-cisternal injection is a relatively simple and safe procedure.

3. Improvement in vision, especially following the first injection, as seen in five cases, is presumptive evidence of the presence of an active infiltrative process in these cases. 
4. Best results may be expected in early cases, with definite defects in part of the field, but with relatively good central vision, at least in one eye, and with little evidence of other nervous involvement.

5. Results would not be expected in late cases, or in advanced cases of paresis. The more general the nervous involvement, even if the atrophy is not advanced, the less chance exists of stopping the process in the nerve.

\section{BIBLIOGRAPHY}

1. Keraval and Raviart.-Arch. de Neurol., 1902, Vol. XIV, p. 336.

2. Marie and Leri -Rev. Neurol., 1904, Vol, XII, p. 190.

3. Stargardt.-Arch. f. Psych. u. Nerv., 1913, Vol. LI, p. 711. Berichtd. Ophthal., Gesell., Heidelberg, 1911, Vol. XXXVII, p. 139; Ibid, 1912, Vol. XXXVIII, p. 214.

4. Richter.-Zeitschr.f. Gesell. Neurol. u. Psych., 1921, Vol. LXVII, p. 1.

5. Head and Fearnsides.-Brain, 1914, Vol. XXXVII, p, 1.

6. Mackintosh and Fildes.-Brain, 1913, Vol. XXXVI, p. 1.

7. Igersheimer.-Deutsch. med. Wochenschr., 1921, No. XXVI. (Also quoted by von Hippel, see below.)

8. Hauptmann.-Zeitschr. f. Gesell. Neurol. u. Psych., 1921, Vol. LXX, p. 245.

9. von Hippel.-Graefe-Saemisch Handb., 1923, p. 432.

10. Paton.-Brit. Jl. of Ophthal., 1922, Vol. VI, p. 289.

11. I waschenkoff, Nonne.-Quoted by Igersheimer, "Syphilis und Auge," Berlin, 1918.

12. Gennerich.-Ibid. Also Gennerich, "Syphilis of the Central Nervous System," 1921.

13. Fordyce.-Amer. Jl. of Med. Sciences, 1921, Vol. CLXI, p. 313.

14. Weed.-Jl. of Med. Res., 1914, Vol. XXIV, p. 1.

15. Schoenberg.-Jl. Amer. Med. Assoc., 1916, Vol. LXVI, p. 2054. N.Y.Jl. of Med., 1918, p. 1.

16. Ayer.-Jl. Amer. Med. Assoc., 1916, Vol. LXVI, p. 2060.

17. Behr.-Klin. Monatsbl. f. Augenheilk., 1916, Vol. LVI, p. 1.

18. Stokes and Osbourne.-Jl. Amer. Med. Assoc,, 1921, Vol. LXXVI, p. 708.

19. Marinesco.-Rev. of Neurol., 1914, Vol. XXII, p. 337.

20. Sicard.-Rev. of Neurol., 1921, Vol. I, p. 325 (Disc), Ibid., p. 1023.

21. Mehrtens and MacArthur.-Arch. of Neurol. and Psych., 1919, Vol. II, p. 369.

22. Goebel.-Zeitschr. f. Augenheilk., 1911, Vol. XXVI, p. 206.

23. Beriel.-Neurol. Centralbl., 1914, Vol. XXXIII, p. 612.

24. Löwenstein.-Vers. der Deutsch. Ophthal. Gesell., 1922.

25. Wegeforth.-Jl. of Med. Res., 1914, Vol. XXIV, p. 129.

26. Suker.-Amer. Jl. of Ophthal., 1920, Vol. III, p. 534.

27. Suker.-Ency. of Ophthal., 1920, Vol. XVI, p. 12478.

28. Hammond and Sharpe,-Jl. Amer. Med. Assoc., 1915, Vol. LXV, p. 2147.

29. Hamill.-Ill. Med. Jl., 1915, Vol. XXIX, p. 204.

30. Campbell and Ballance.-Lancet, 1914, Vol I, p. 1529 ; Brit. Med. Jl,, 1914, Vol. I, p. 596 ; Lancet, 1919, Vol. I, p. 608.

31. Gifford, S. R.-Nebr. Med. Jl., 1922, Vol. VII, p. 408. 